\title{
Impact of Leaders \\ The Impact of the Engagement of Local Government Leaders' on the Effectiveness of Participatory Planning as Found in the Local Community Academy Program $^{1}$ (2014-2015)
}

\author{
Róza SZÁMADÓ2 \\ "Paradoxically, the enduring competitive advantages in a global economy \\ lie increasingly in local things_-knowledge, relationships, \\ and motivation that distant rivals cannot match" \\ Michael E. Porter [1]
}

\begin{abstract}
The relevance of the above quotation from an excellent author and economist, adapted to present day Hungarian local governments, is unquestionable. At the beginning of the $21^{\text {st }}$ century, in a globalizing world, the demand for the direct inclusion of independent social groups and individuals and the maintenance of the communities within geographical localities have become a primary issue as opposed to the conditions under the alienating, technocratic, impersonalizing and centralized political regimes of the Europe of the second half of the past century. For this reason, the importance of the role of local leadership is magnified.

The program included training for the local governments in the convergence regions, and had three pillars. The first pillar includes 6 post graduate e-learning training programs studied by approximately twenty thousand public officers. The second pillar is the network of the so-called Local Community Academies, comprising the elaboration of strategic methodologies by local participants to be recommended to local governments. The third pillar supported the traditional classroom training for three hundred local government employees.

The program of the Local Community Academies (LCA) aimed to support the social inclusion, and the ability of strategy-making. This study aims to answer the following research question: "How did the engagement and involvement of local government leaders, affect participatory planning during implementation of the LCA program?" The relevant research method is an empirical analysis of survey data and final reports.
\end{abstract}

Keywords: participatory planning, engagement, inclusion, successful community collaborations

1 This study is based on the surveys and final reports of Program ÁROP 2.2.22 titled "Training for the Local Governments of the Convergence Regions” conducted at the National University of Public Service, Hungary.

2 National University of Public Service, Ph.D. student; e-mail: rszamado@gmail.com 
Róza SZÁMADÓ: Impact of Leaders. The Impact of the Engagement of Local Government Leaders’...

\section{Introduction}

\section{Background and Justification of the Topic}

At the time of the political economic transition of Central Europe in 1990, there was a law defining the system of local governance with considerable administrative functions delegated to the municipalities. After two decades, in 2011, the CLXXXIX law on local governments (Mötv.) redefined their role.

Local governance significantly stepped out of public administration allocation, since some of its tasks had been transferred to the district (borough) offices from 2013 on. With the requirements of the Mötv. the local government system has changed, significantly, and in its new position:

- local governments have to fulfil their duties in a new way;

- they have to follow a task-based supporting system instead of normative financing;

- in the new local governance office system, the number of offices dropped;

- the county governments also have a new role in which they provide regional development tasks;

- instead of legal control, legal supervision was introduced with broader powers in local governance system.

As a result of the administrative reform, the focal tasks regarding local development are paid more attention to than state administration tasks. In order to achieve modern public management and services, in inclusive development, it is necessary to continue the reforms and to support and develop the stakeholders. The strengthening of the self-supporting capacity, the exploration, exploitation of the local resources, and application of the principle of self-reliance are the new expectations formulated in the Mötv. All this anticipates that the stakeholders responsible for the leadership of the settlements have to act not only as local politicians, but as urban managers as well, what is more, they should become mediators, experts and facilitators during the design and implementation of modern public services and during the involvement of the civil, economic and non-governmental actors if they wish to be successful in local development.

The readjustment of tasks between the central government and the local governments essentially limited the operation of the local governments as quasi-decentralized bodies. In quite a few magisterial and public service functions the local government used to be the supplier of the services financed and supervised by the central government.

The changes opened up the possibility for the local and county governments to focus on the organization and management of the local communities, the strengthening of the local economy as autonomous actors, rather than on the local suppliers of the functions of the state.

Adapting quickly and efficiently to the changing regulatory, economic and social environment has continuously been a challenge for local governments, especially when new expectations stemming from new functions are considered. Educating and training local government officials in order to increase their personal and professional skills will lead to vast improvement in their ability to meet these challenges.

In the light of the new circumstances the roles of leaders and leading bodies of towns need to be changed as well. For better local governance, a paradigm shift is necessary. Instead of 
Róza SZÁMADÓ: Impact of Leaders. The Impact of the Engagement of Local Government Leaders’...

political leadership, the focus should move to managing local affairs, local leaders ought to become the managers of their communities and they should attempt to redefine their roles.

\section{About the Program}

In 2013-2015 a new type of post graduate training program was developed and piloted in Hungary at the Institute for Executive Training and Continuing Education within the National University of Public Service (NUPS). Although the pilot included methods which were established earlier, such as interactivity during the training, this was the first in the period when the principles of the European Union 2020 Strategy were declared regarding economic growth: smartness, sustainability and inclusiveness. (Figure 1) All of these were represented by the 3 pillars of the Program such as e-learning, class training and field training with the inclusion of the local population. [2]

\section{ÁROP 2.2.22 Training for the Local Governments of the Convergence Regions}

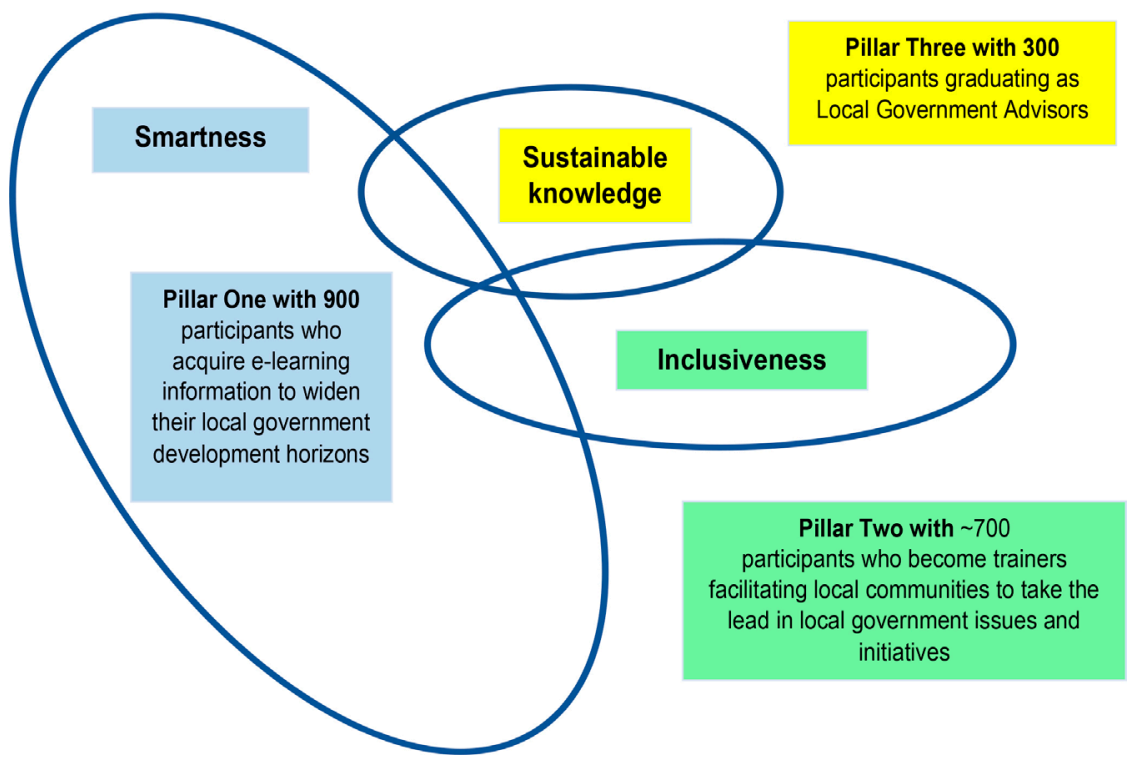

Figure 1. The realization of the "Flagship" Program meeting the requirements of Europe 2020

Directive and the call for modernization both in technological and social aspects. [2: 38]

The training program is meant for the local governments in the convergence regions, consisting of three pillars. The first pillar includes the annual post graduate e-learning training programs of approximately twenty thousand public officers. The second pillar is the network of the so called Local Community Academies. It comprises the elaboration of strategic methodologies by local participants to be recommended to the local governments. The third pillar supports the traditional training of three hundred local government employees.

Under the LCA program, 77 pilot trainings were conducted. The program had four objectives: 
1. With trainer assistance, during workshops, the participants have to plan development strategies to follow in the forthcoming period.

2. Provide an opportunity for participants to experience the benefits of participatory planning and the advantages of workshops on which Community leaders can rely in order to correctly apply the new methodologies.

3. Implementation of increased and continually increasing public inclusiveness, ensuring the widest possible dissemination of the outcomes of synergy and multiplication.

4. The LCA methodology has to be reviewed and finalized in a way that is fitted to the local government practice and is relying on the experiences of the pilot program.

The LCA methodology followed the local actors step by step through the process of agreeing on common objectives, planning actions required to complete the design and the development of procedures for monitoring the implementation process. Methodology intensive sections (i.e. training - working together workshops in nature) and deepening of the sections (i.e. activity between training days conducted by the participants) are both included.

Table 1. Agenda outline of preparatory meetings for each workshop day. [3: 6]

\begin{tabular}{|l|l|l|l|}
\hline Introductory meeting & 1. workshop day & 2. workshop day & 3. workshop day \\
\hline Introductory meeting & Vision for the future & Value program & Program Catalogue \\
\hline Program description & SWOT & Goal system & Control \\
\hline Stakeholder analysis & Programs & Program catalogue & Display \\
\hline
\end{tabular}

The program implementation data:

- representing 77 settlements, 4 of which piloting;

- 308 workshop days;

- 3 leading trainers and 1 consulting trainer;

- 18 trainers;

- 5 experts;

- 12 training assistants;

- a team of 6 professional consultants;

- a team of 10 project managers.

\section{Documents and Data Used}

Since the key objective of the ÁROP Program was the development of a practical methodology taking into account real local demands and to be used by municipal leaders, the execution of the Program was accompanied by a continuous monitoring that resulted in precise and detailed data for further analysis of the Program. During the implementation of LCA Pillar 2, the author of this study, as the leading trainer, had full access and insight regarding the qualitative and quantitative data collection results.

The primary data which were used for statistical analysis were continuously collected. The number of participants from the 77 settlements on each workshop day, the number of organizations represented and the number of local municipal leaders' attendances were all recorded as qualitative data. Local municipal leaders include mayors, notaries and other municipal executives or local representatives. 
To validate the final methodology through practical experience there was full professional monitoring applied to each step of the process, performed by the trainers' daily reports. In the final stage of the program the trainers accomplished the evaluation of all the 77 settlements on the basis of a uniform criteria assessment. The results of the program implementation were then evaluated and summarized on the basis of the trainers' reports. [6] In addition, prior to the closing of the program, there was a follow-up monitoring and an impact assessment analysis performed by independent experts. [7] [8] The accurate recording of these findings and the attendance data allowed the survey regarding the presence and participation of the leadership, the commitment, the implementation and impact assessment to be presented in this study.

\section{Research Theory and Methodological Framework}

\section{Participatory Planning ${ }^{3}$ [4]}

According to the United Nations Centre for Human Settlements (UNCHS) Habitat study participatory planning is a participatory process aimed at defining, proposing and an enforcing management plan on issues of common interest. Emphasis is placed on the management of planning as an approach that allows the integration of the knowledge of stakeholders, scientists and policy-makers, thus stimulating participatory research and action. Typically, participatory planning is an opportunity to tailor management rules at local/regional scale according to stakeholder needs. With the aim of contributing to the establishment of a bottom-up approach rather than the typical top-down approach, one can also integrate experience based and research based knowledge. Participation can be defined as "the process of decision-making and problem solving, involving individuals and groups who represents diverse interests, expertise and points of view, and who act for the good of all those affected by the decisions they make and the actions that follow". [4: 140] "Participatory planning aims to harmonize views among all of its participants as well as prevent conflict between opposing parties. In addition, marginalized groups have an opportunity to participate in the planning process.” [5: 183]

The National Civic League (NCL), collaborating with others, conducted major studies in the early 1990's in the USA to determine why some communities were more successful than others in working effectively across political, social and economic boundaries.

Their research included over fifty in-depth studies of successful community collaborations. According to the NCL findings, the following issues have to be present or deliberately built into the process from the beginning in order for successful collaboration:

- Good timing and clear requirements.

- Strong stakeholder groups.

- Comprehensive. Are all the issues addressed and are the sectors, concerned with them, informed, included and well represented in order to avoid single sector domination?

- Credibility and transparency of the process.

- Commitment and/or engagement of high level leaders. If the mayor, for example, cannot be involved, does he or she delegate a representative with decision-making authority? Are the citizens or civic society organizations putting forth their best representatives for participation?

3 Based on Building Bridges between citizens and local governments to work more effectively together through participatory planning, UNCHS Habitat. 
Róza SZÁMADÓ: Impact of Leaders. The Impact of the Engagement of Local Government Leaders’...

- Support or acquiescence of "established" authorities or powers.

- Overcoming mistrust and scepticism.

- Strong management of the process. Has the process of collaboration been managed effectively?

- Interim successes. Have intermediate successes been achieved, built on, acknowledged and celebrated to provide encouragement and sustainability?

- A shift to broader concerns. [4]

\section{Research Methodology}

The examination of the completion of the above-mentioned 10 key elements-within the framework of the LCA program - is very interesting, though out of the scope of this study.

This study is primarily concerned with the fifth success factor namely "Commitment and/ or involvement of high level Leaders". The reason for this is that trainers and experts produced a variety of summary materials indicating that the commitment of municipal leaders was a key addition to the program.

The impact of commitment from leaders during the LCA program to success for grouping will be examined on the following issues:

- Is the presence of municipal leaders realized in the process and to what extent?

- What was the impact of participation from local government leaders with regards to the first goal of the program? (Work out development strategies with the settlements within the framework of workshops that provide guidance for the next period.)

The examination of inclusive local government operations, in this case through the involvement and commitment of local government leaders, is also a subject to personal and research interest.

\section{Evaluation of Results}

\section{Analysis of Data and Documents Used as a Basis}

Under the ÁROP 2.2.22. Project “Training for local governments in convergence regions" 77 settlements accomplished community based development strategies with the provided framework studied in the research.

During the LCA program $1+3$ day schedules took place. The first day of the program was dedicated to preparation in which the allotted time of the vast majority of cases proved to be sufficient. However, there were a number of places encountered where the efficiency and working conditions of some groups required up to two days more. The second half of the last day of the programs aimed at disseminating local LCA results, for which the leadership of the neighbouring villages were also invited.

The program consisted of 308 workshop days. Each group work session made attendance sheets, in which the delegating organization and the position of the delegate was noted. Based on these attendance sheets, the attendance of local government officials and leaders can be measured. 


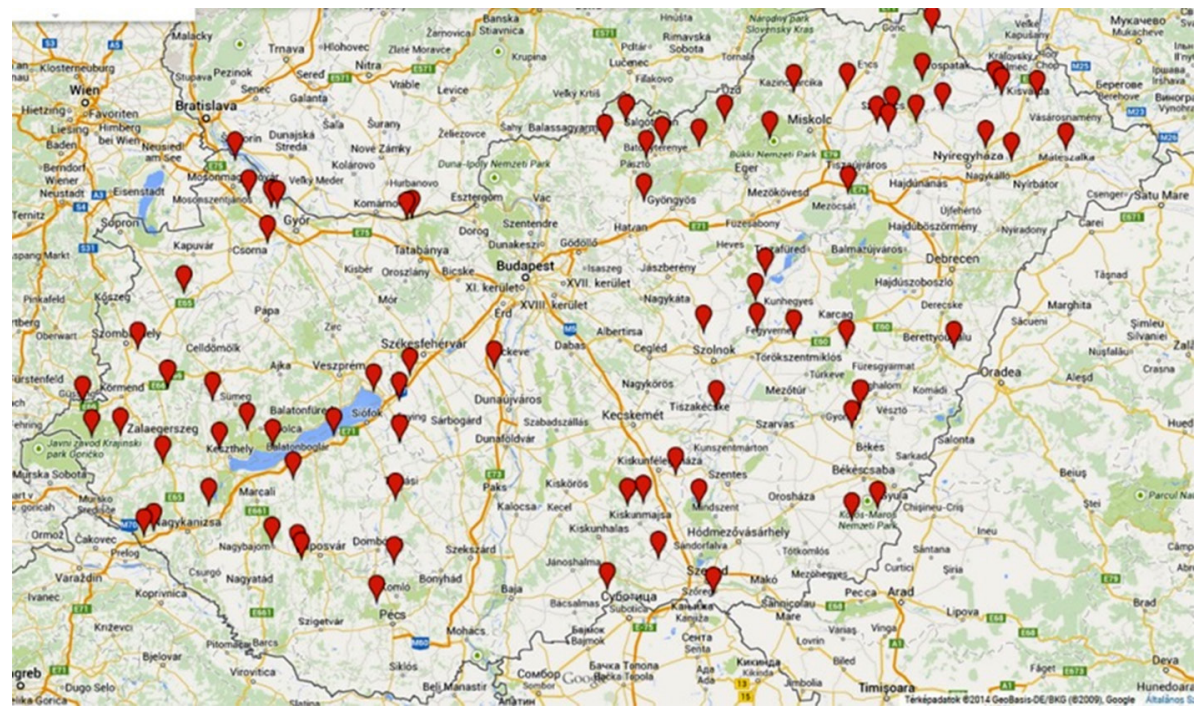

Figure 2. LCA locations in Hungary. [9]

The overall objective of the program was not only to implement local settlement LCA-s, but also to develop a final framework based on experiences in practice. Therefore, continuous monitoring and feedback were especially important.

The LCA trainers prepared their reports and evaluated the results after the program, both in general and in connection with their settlements. Using the materials from the results and experiences of the program, the summary document titled "LCA content analysis" was created.

The role of settlement leaders in the efficiency of the program was emphasized. The majority of trainers indicated that one key to the success of the program are the leader/s of the settlement. The commitment of the mayor and council to the LCA program largely determined the outcome of the program. If the mayor does not support or perchance is hostile to the program, the program will likely be a failure. [6]

Experts in the feedback conference for evaluating the entire program agreed in relation to the timing. "The timing was good, since the governments were required to accept their economic program within a fixed period of time. Municipalities with such legislative or other obligations in the future should pay attention to it.” [6]

Concerning the efficiency of the strategy development workshop series "we can say that the project has significantly improved the strategic planning capacities of local governments; considering that the previous situation was characterized as mediocre in municipalities. It is important that governments and leaders have changed their approach to overall strategy and see the benefits of creating professional strategy", [7: 46] according to the monitoring report [7] and the post impact assessment. [8]

Leaders interviewed in the post impact assessment agree that local government improved their abilities to accept new strategies internally and strategies are thought of as more important issues than before. Two thirds of the interviewees thought that it became much more important, the remaining third said it became more important than previously. 
Róza SZÁMADÓ: Impact of Leaders. The Impact of the Engagement of Local Government Leaders’...

Has involvement improved ability to...

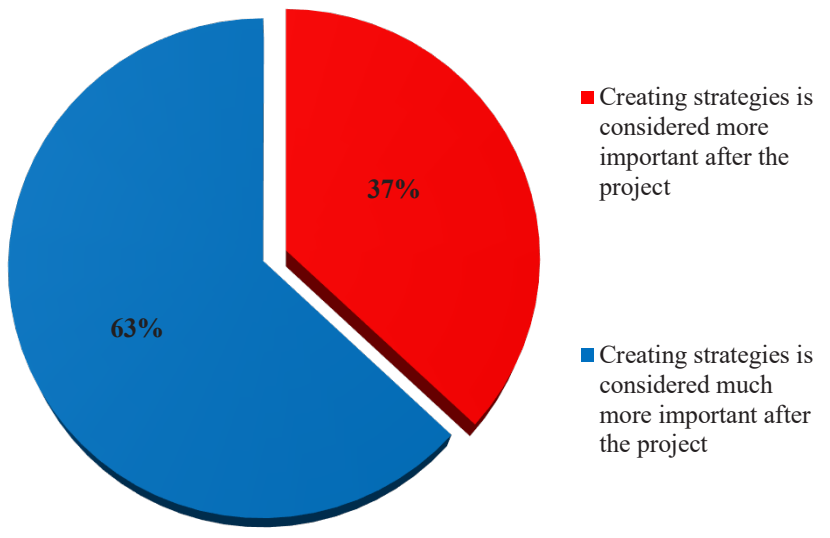

Figure 3. The necessity of creating strategies. ${ }^{4}$ [7: 52]

\section{Evaluation of Results}

During the program, 308 workshop days were organized and 3,008 participants took part in them. 303 of them were local government leaders, which represents $10 \%$ average leadership presence based on the time sheets.

Each of the 77 municipalities prepared relevant documents for at least a strategic base material. The distribution of strategic documents (49 pieces) and other materials (28 pieces) is illustrated in the Figure 4.

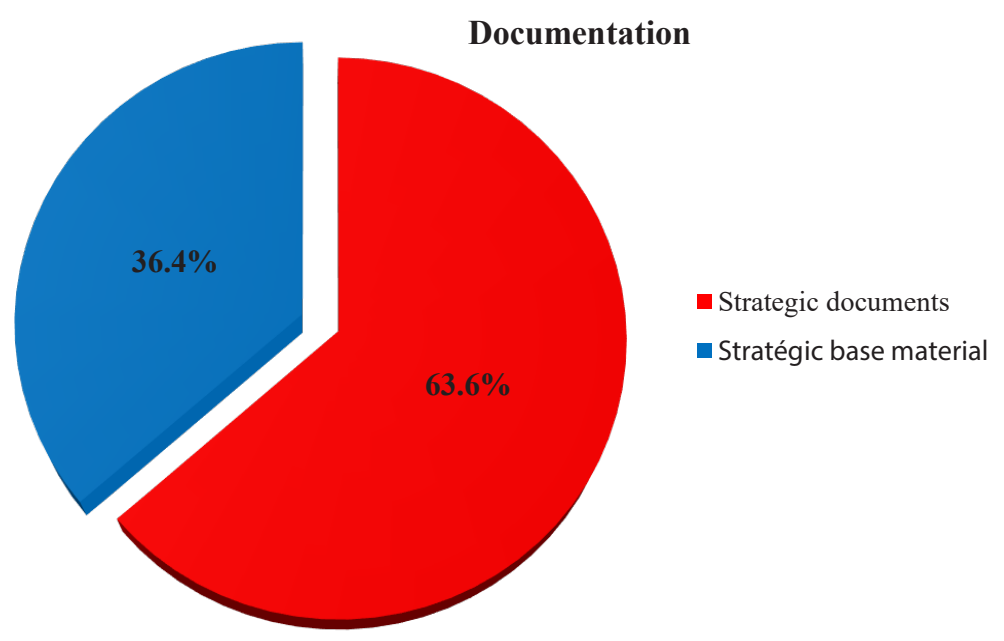

Figure 4. The distribution of the documents. [6: 1]

4 According to reports of trainers.

5 According to reports of trainers. 
The trainers in their final reports (with the exception of 5 cases) evaluated the accomplished documents. According to the trainers the quality of the created documents is outstanding. The trainers rated the documents on a scale of 1 through 5. Most of those (66 pieces) were graded 4 or 5 . The next table shows their distribution.

Table 2. The quality of accomplished documents according to the trainers. [6: 2]

\begin{tabular}{|l|c|c|}
\hline Type of document & Number of copies & Average quality \\
\hline Complete strategical documents & 31 & 4.58 \\
\hline Strategical documents still in development & 16 & 4.50 \\
\hline Strategical base documents & 25 & 3.96 \\
\hline Summary & $\mathbf{7 2}$ & $\mathbf{4 . 3 5}$ \\
\hline
\end{tabular}

During the post LCA program assessment it was revealed if the settlements will use the accomplished documents.

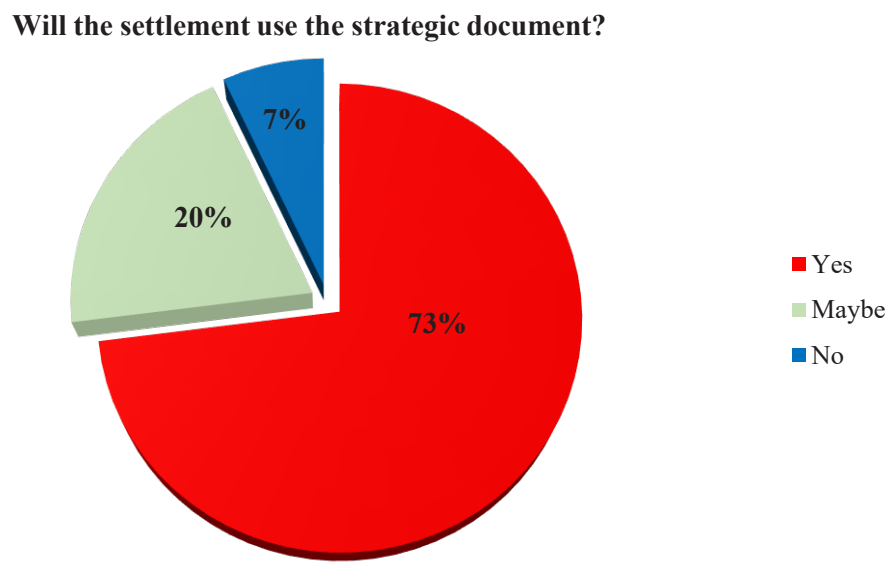

Figure 5. The use of the accomplished documents.

(Based on source [6] edited by the author.)

The overwhelming majority of ideas and action plans had formal post-program effects, because the local officials built them into their various strategies. This was mainly done for economic programs; however, some have been included in the Integrated Urban Development Strategies.

There are cases where some parts of the documents were incorporated during the discussions of budget. An example of this would be the formation of community gardens. In three cases the local government will not use the document. The reason for this are as follows:

- Poor quality of strategic preliminary materials.

- The municipal leadership and the delegates showed little or no interest in the program. During the process the trainers evaluated the degree of perceived support of the local government management (mayors, clerks, board members) in 64 cases. 


\section{Support from the local goverment leadership}

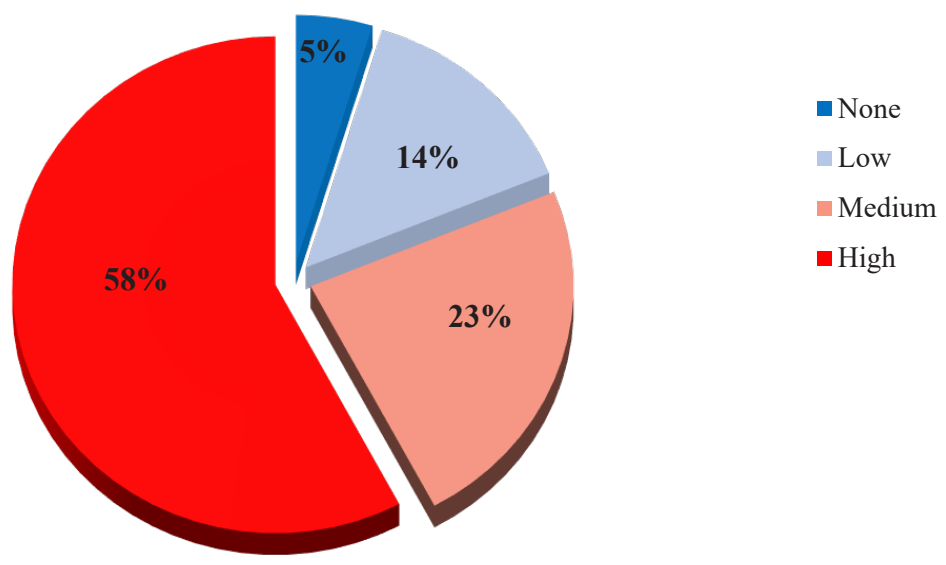

Figure 6. The support from local government leaders perceived by the trainers. [6: 11]

Based on the chart it seems that the majority of government leadership supported the program, which is in line with the results of monitoring and assessment. The complete lack of managerial support was reported by $5 \%$ of the trainers.

The objective of the survey was to reveal the impact of the leadership commitment and participation on the success of the LCA. The settlements were the basic units of the research. The leadership commitment and the participation were measured by the number of attendants, the number of attendants from the public sector, and the number of the local leaders (mayors, notaries, executives, representatives, see Table 3).

Table 3. Measuring variables of the commitment and participation. [Edited by the author.]

\begin{tabular}{|l|l|l|}
\hline Variable & Description & Measure \\
\hline Number of attendants & Workshop attendants form the settlement & scale \\
\hline $\begin{array}{l}\text { Number of public service } \\
\text { attendants }\end{array}$ & $\begin{array}{l}\text { Public service attendants from the } \\
\text { settlements }\end{array}$ & scale \\
\hline Number of local leaders & Local leaders from the settlement & scale \\
\hline
\end{tabular}

There were 77 settlements in the sample. Their average population number was 2246.22, with a deviation of 1194.10

The parameters of the commitment and participation for the 77 settlements can be seen in Table 4. The number of attendants varies from 16 to 104 . There were 38 or more attendants from half of the settlements. The average number of public sector attendants is 23.87, with 9.87 digressions from the average. The average number of the local leadership attendance is 1.92, with 2.85 digressions. 
Róza SZÁMADÓ: Impact of Leaders. The Impact of the Engagement of Local Government Leaders’...

Table 4. Parameters of commitment and participation. [Edited by the author.]

\begin{tabular}{|l|l|l|l|l|l|l|}
\hline Variable & N & Min & Max & Med & Avg & S.D. \\
\hline Number of attendants & 77 & 16 & 104 & 38 & 39.06 & 14.74 \\
\hline Public sector attendants & 77 & 9 & 54 & 22 & 23.87 & 9.867 \\
\hline Local leadership attendants & 77 & 0 & 14 & 1 & 1.92 & 2.85 \\
\hline
\end{tabular}

Note: $N=$ samples size, Min = minimum, Max = maximum, Med = median, Avg = mean,

S.D. = standard deviation

Efficiency was measured with the readiness of the strategic documents and their application. (Table 5)

Table 5. Variables in measuring efficiency. [Edited by the author.]

\begin{tabular}{|l|l|l|l|}
\hline Variable & Description & Values & Measure \\
\hline $\begin{array}{l}\text { Readiness of strategic } \\
\text { documents }\end{array}$ & $\begin{array}{l}\text { Is there a strategic closing } \\
\text { document? }\end{array}$ & $\begin{array}{l}\text { 0: no } \\
1: \text { will be } \\
2: \text { yes }\end{array}$ & ordinal \\
\hline $\begin{array}{l}\text { Application of strategic } \\
\text { documents }\end{array}$ & $\begin{array}{l}\text { Is it applied by the local } \\
\text { government? }\end{array}$ & $\begin{array}{l}0: \text { no } \\
1: \text { occasionally } \\
2: \text { yes }\end{array}$ & ordinal \\
\hline
\end{tabular}

As an integration of the above two parameters, a new one was calculated, efficiency. The new parameter measures efficiency on an ordinal scale. There were 4 settlements with missing responses, so the sample consists of 73 elements in this aspect. On the basis of the responses the frequencies of the values can be seen in Table 6 . The most frequent response " 0 : there is no strategic closing document or application" occurs with $38.4 \%$ of the respondents. The median of efficiency is 3, i.e. half of the respondents have 3 or 4 efficiency level. It means there will be a strategic closing document applied, or there is a strategic closing document that is applied occasionally, or there is one applied already. 
Róza SZÁMADÓ: Impact of Leaders. The Impact of the Engagement of Local Government Leaders’...

Table 6. Parameters of efficiency variable. [Edited by the author.]

\begin{tabular}{|l|l|l|l|}
\hline Variable & Values & Frequency & $\begin{array}{l}\text { Relative } \\
\text { frequency, } \\
\text { \% }\end{array}$ \\
\hline Efficiency & $\begin{array}{l}\text { 0: there is no strategic closing document applied } \\
\text { 1: there will be strategic closing document, but } \\
\text { not applied }\end{array}$ & 28 & 38.4 \\
& $\begin{array}{l}\text { 2: there will be a strategic closing document to } \\
\text { be applied occasionally, or there is one but not } \\
\text { applied } \\
\text { 3: there will be a strategic closing document to be } \\
\text { applied, or there is one with occasional applica- } \\
\text { tion }\end{array}$ & 2 & 0 \\
\hline & $\begin{array}{l}\text { 4: there is a strategic closing document applied } \\
\text { Sum }\end{array}$ & 25 & 24.7 \\
\hline
\end{tabular}

The connection of commitment and participation was examined with the efficiency variable, the Spearman Correlation Coefficients and its significance test. ${ }^{6}$ Table 7 shows the results. There were positive correlations found in all 3 cases. Regarding the number of attendants: 0.041, regarding the public service attendants: 0.065, regarding local leadership attendance: 0.069, i.e. the higher the leadership commitment and attendance, the stronger the efficiency is. However, in neither case was there a significant correlation found with the Spearman Correlation Coefficients (on 5\% significance level).

Table 7. Correlation between commitment, participation and efficiency. [Edited by the author.]

\begin{tabular}{|c|c|c|c|c|}
\hline & \multicolumn{4}{|l|}{ Efficiency } \\
\hline & $\mathbf{N}$ & rho & sig & \\
\hline \multirow{3}{*}{$\begin{array}{l}\text { Commitment and } \\
\text { participation }\end{array}$} & Number of attendants & 73 & 0.041 & 0.728 \\
\hline & Public service attendants & 73 & 0.065 & 0.588 \\
\hline & $\begin{array}{l}\text { Number of local leader- } \\
\text { ship attendance }\end{array}$ & 73 & 0.069 & 0.560 \\
\hline
\end{tabular}

Note: $N$ = samples size, $r$ o $=$ Spearman's rho

6 The efficiency variable was measured on an ordinal scale, while the variables of commitment and participation were measured on a ratio scale; therefore, the Spearman Rank Correlation Coefficient is suitable to indicate the connection. 
Róza SZÁMADÓ: Impact of Leaders. The Impact of the Engagement of Local Government Leaders’...

The non-significant state of the correlation coefficient draws attention to the fact that commitment and attendance are not enough to guarantee efficiency to explain which requires further variables to take into account.

This study aims to answer two questions based on results of the LCA program:

1. Is the presence of municipal leaders realized in the process and to what extent?

2. What was the impact of participation from local government leaders with regards to the first goal of the program? (Work out development strategies with the settlements within the framework of workshops that provide guidance for the next period.)

The answer to the first question is clear from the data on participation. Among all of the participants roughly 10 percent were local government leaders. This was sufficient during the program for the key success factor set up by the NCL.

The answer to the second question consists of many parts:

1. Out of the 77 settlements 74 succeeded in developing strategic documents which is 97\%. (Figure 4) There were 46 completed development strategies and 28 collections of documents capable of being turned into acceptable strategies. This output is very significant.

2. The local government accepts the LCA development strategy. (Figure 6)

$$
\text { Yes: } 73 \% \quad \text { Partly: } 20 \% \quad \text { No: } 7 \% \text {. }
$$

These results speak for themselves and the complete or partial incorporation of $93 \%$ of the designs and results of the program indicate a serious impact on local leaders and a significant success for the program.

3. Home municipality support (According to the trainer: What was the level of openness and supportive behaviour on behalf of the local government representatives?) (Figure 7)

$$
\text { High: } 58 \% \quad \text { Medium: } 23 \% \text { Low: } 14 \% \quad \text { None: } 5 \%
$$

The degree of support by local government leaders supports the findings of the post impact assessment, which stated that local government leaders perceived the effects of the program to be significant regarding the improvement of strategic planning skills and abilities.

4. The timing of the program

The LCA programs were conducted soon after the 2014 local government elections, which increased the involvement and commitment from the leadership according to opinions of reports and assessments. The main reason for this is that settlements needed to create economic programs, which would benefit from the workshop documents compiled during the program. This claim is supported by the high number of incorporated documents.

5. Executive isolation, rejection

In the three settlements where there was no leadership involvement, interest and/or the program was rejected, no appreciable quality document was elaborated and submitted to the Local Government Council.

All three of the correlation coefficients are low, implying a weak connection, however, in all three cases there was a positive relationship demonstrated. This means that the higher the engagement and participation, the better performance indicators are forecasted. Nonetheless, the correlation coefficients being not significant calls attention to the fact that, participation and commitment of the leaders by itself does not guarantee effectiveness. More variables need to be studied to explain effectiveness. 


\section{Conclusions}

Overall results of the program show that the leaders of local governments' involvement and commitment have a significant impact on the participation and performance of the design process. According to the findings of the program, special attention should be paid to the involvement and commitment of the local municipality leaders. Further studies should be conducted to explore deeper relationships between the efficiency factors presented on participatory planning in order to reduce the risks therein.

\section{References}

[1] PORTER, M. E.: Clusters and the New Economics of Competition. Knowledge stream, innovative systems, regional networks - Theoretical and Methodological mainstreams, international and domestic experiences. Győr: MTA RKK NYUTI, 2004.

[2] TÓZSA I.: A New Approach Model in Post Graduate Training of Local Government Officers. Journal of Public Management Research, 11 (2015), 30-45. DOI: https:// doi.org/10.5296/jpmr.v1i1.7592

[3] MOLNÁR K.: Community based local development strategy creation, method suggestions and extension. Budapest: NKE, 2015.

[4] FISHER, F.: Building Bridges between citizens and local governments to work more effectively together through participatory planning. Nairobi: UNCHS Habitat, 2001. http:// mirror.unhabitat.org/pmss/getElectronicVersion.asp?nr=1371\&alt=1 (Downloaded: 282 2016)

[5] McTAGUE, C., JAKUBOWSKI, S. Marching to the beat of a silent drum: Wasted consensus-building and failed neighborhood participatory planning. Applied Geography, 44 (2013), 182-191. DOI: https://doi.org/10.1016/j.apgeog.2013.07.019

[6] BRECSOK A. Á.: The content analysis of the experiences and results form the LCA program. Budapest: NKE, 2015. (An internal document of the project - written with professional guidance from Mátyás Gáspár LCA pillar manager.)

[7] NAVIDEA Ltd.: Post impact assessment of change in strategy creation ability - "training for local governments in convergence regions” based on HKA pillars. Budapest, 2015.

[8] NAVIDEA Ltd.: Monitoring report: "training for local governments in convergence regions” based on HKA pillars. Budapest, 2015.

[9] TRELLO: HKA települések. 2014. 09. 18. https://trello.com/c/ZXkmiFul/30-a-hka-terkep-acsatolasban-talalhato-alabbi-linkre-kattintva-elerheto-a-helyi-kozossegi-akademiakhalozatanak-folyamatosan-aktua (Downloaded: 282 2016) 